\title{
Effects of the Pilates method on neck pain: a systematic review
}

\author{
Efeitos do método Pilates nas dores cervicais: uma revisão sistemática
}

\author{
Natália Fernanda Cemin, Emanuelle Francine Detogni Schmit, Cláudia Tarragô Candotti*
}

Universidade Federal do Rio Grande do Sul (UFRGS), Porto Alegre, RS, Brazil

\begin{abstract}
Introduction: The Pilates method has been used for neck pain reduction. Objective: To systematically review randomized and non-randomized controlled trials that assessed the effects of Pilates on neck pain when compared to other groups (CRD42015025987). Methods: This study involved a systematic review directed by the PRISMA Statement based on the recommendations of the Cochrane Colaboration, registered in PROSPERO under the code CRD42015025987. The following databases were searched: Cochrane CENTRAL, EMBASE, PubMed, Science Direct, Scopus and Web of Science, using the terms "Pilates" AND "Neck pain", without language and date restrictions. Results: Of a total of 73 identified studies, two were included herein since they fulfilled the eligibility criteria (at least one intervention group applying Pilates), where we evaluated the methodological quality by the Downs and Black scale and evidence strength with the Best Evidence Synthesis. Pain and disability decreased from the sixth session, with gradual improvement in up to 24 sessions. Conclusion: Few studies are available using Pilates to decrease pain, and moderate evidence exists of positive Pilates effects on pain and function in patients with neck pain.
\end{abstract}

Keywords: Neck Pain. Pilates. Exercise Therapy. Systematic Review.

\section{Resumo}

Introdução: OMétodo Pilates vem sendo utilizado para reduçãóálgica cervical. Objetivo: revisar sistematicamente os ensaios clínicos aleatorizados e não aleatorizados que avaliaram os efeitos do Método Pilates na dor cervical,

\footnotetext{
* NFC: BS, e-mail: nataliacemin@gmail.com

EFDS: Doctoral Student, e-mail: manu_schmit@hotmail.com

CTC: PhD, e-mail: 00061969@ufrgs.br
} 
quando comparados a outro grupo (CRD42015025987). Métodos: O presente estudo compreendeu uma revisão sistemática direcionada pelo PRISMA Statement com base nas recomendações da Colaboração Cochrane, registrada no PROSPERO sob o código CRD42015025987. Foram conduzidas buscas nas bases de dados Cochrane CENTRAL, EMBASE, PubMed, Science Direct, SCOPUS e Web of Science, com os termos "Pilates" AND "Neck pain", sem restrição de idioma e data. Resultados: Dos 73 estudos identificados, dois foram incluídos por cumprir o critério de elegibilidade (ao menos um grupo com intervenção com Pilates), sendo a qualidade metodológica avaliada pela escala Downs e Black e a força de evidência pela Melhor Síntese de Evidência. A dor e a incapacidade diminuem a partir da sexta sessão, com melhora gradativa até 24 sessões. Conclusão: Há poucos estudos e moderada evidência sobre os efeitos positivos do Pilates na dor e funcionalidade em indivíduos com dor cervical.

Palavras-chave: Dor Cervical. Pilates. Terapia por Exercício. Revisão Sistemática.

\section{Introduction}

Chronic neck pain is characterized by pain and limited movement, from small discomforts to severe and disabling pain $[1,2]$. This condition causes reduction in quality of life [3], leading to drug dependence, emotional changes and difficulties at work $[4,5]$. Approximately 14 to $71 \%$ of adults will present an episode of neck pain at some point in their life, with annual prevalence varying from 16 to $75 \%$ [6] and a recurrence rate of $75 \%$ in the following five years [7]. According to Ferreira et al. [8], in a study conducted with 972 Brazilians aged 20 to 69, $24 \%$ of the individuals presented neck pain at least once in the last year, with a prevalence of chronic pain at $18.9 \%$ and acute pain at $34.1 \%$. Similar results are observed in other countries. For example, in a Finnish study [9], chronic neck pain was observed in 13.5\% of women and $9.5 \%$ of men, and in a Norwegian study [10], 13.8\% of the participants reported pain lasting over six months, while in individuals over the age of 43 this rate rose to $20 \%$.

Currently, several types of interventions have been performed in order to reduce chronic neck pain [11 - 13], from conventional physiotherapy to more specific exercises $[14,15]$, among them the Pilates method $[16,17]$. Pilates can be considered as an alternative to improve flexibility, motor coordination, muscular strength and stability, as well as postural alignment, which are essential factors for postural functionality and reeducation [18 - 20] in general.

In addition, strengthening and resistance exercises, specific for the cervico-scapulothoracic and shoulder region, have been highlighted as a beneficial part of the intervention routine of patients with chronic neck pain, presenting moderate evidence levels regarding pain relief and functional improvement [13]. The Pilates method comprises the accomplishment of global muscular activations [18 - 20] in its repertoire of exercises, although it is possible to isolate muscular focus and prioritize regions of interest according to the presented pathology, and can, thus, be recommended for interventions in individuals with neck pain.

However, there is no evidence so far for Pilates prescription for neck pain and functional improvement. Thus, the aim of the present study was to systematically review randomized and non-randomized clinical trials that evaluated the effects of the Pilates method on neck pain when compared to a control group or to another type of intervention.

\section{Methods}

\section{Study type}

The present study comprised a systematic review [21] guided by the PRISMA Statement [22] based on the recommendations of the Cochrane Collaboration [23], registered in PROSPERO under the code CRD42015025987 (http://www.crd.york.ac.uk/PROSPERO/display_ record.asp?ID=CRD42015025987).

\section{Search strategies}

In order to achieve the proposed goal, the following Cochrane databases were searched: CENTRAL, EMBASE, PubMed, Science Direct, SCOPUS and Web of Science, between September 4 and 9, 2015. The terms and boolean operator searched for were "Pilates" AND "Neck pain". No restriction regarding language 
or year of publication was applied, and the search ranged from the beginning of the establishment of the databases until the search year, 2015. An example of the search strategy is presented in Table 1 . Studies should be clinical trials published in peer-reviewed journals or papers published in annals of events. Manual searches were also performed based on the references of the included studies.

Table 1 -Search strategy - PubMed

\begin{tabular}{ll}
\hline$\# 1$ & "Pilates" \\
$\# 2$ & "Neck Pain"[Mesh] OR "Neck Pain" \\
$\# 3$ & \#1 AND \#2 \\
\hline
\end{tabular}

\section{Elegibility criteria}

Two evaluators, independently selected the potentially relevant studies from the search results titles and abstracts. When these sections did not provide enough information to be included, the full text was verified. Subsequently, the same reviewers independently evaluated the complete studies and performed the selection according to the eligibility criteria: a methodology that involved a Pilates method intervention in at least one group. Discordant cases were resolved by consensus [24]. Authors, year of publication, participants (total and group - age), type of intervention and results of the variables of interest (pain and functionality) were independently obtained by the two reviewers, using a standardized form.

\section{Evaluation of the selected studies}

The two reviewers independently assessed the methodological quality and risk of bias through the Downs and Black scale [25], which is composed of 27 items distributed in five sub-scales (report, external validity, risk of bias, confusion factors and power of study). The answers were scored as zero (item not included) or one (item included), with the exception of one item of the sub-scale report, that scores from zero to two and the item referring to the power of the study, which scores from zero to five. However, it should be pointed out that, in studies involving oriented physical activity as a form of intervention, as in the case of this review, items 14 and 24 were not be considered, since it is not possible to blind individuals and therapists.
Thus, the maximum score obtained for the studies was 30 , with a cut-off point of 18 points chosen to discriminate between low and high quality studies.

\section{Evidence strength}

The strength of the scientific evidence was analyzed through the Best Evidence Synthesis [26], based on the following criteria: strong evidence, obtained through several high-quality studies; moderate evidence obtained through a high quality study and one or more low quality studies, limited evidence obtained through a high quality study or several low quality studies; and no evidence, obtained through a poor quality study or contradictory results.

\section{Results}

The initial search identified 73 studies, of which 12 were duplicates, thus leaving 61, although 59 were excluded based on the titles and abstracts. Thus, only two were eligible for a detailed analysis and were included in this review. Figure 1 displays the flowchart of the search and Table 2 summarizes the characteristics of the included studies.
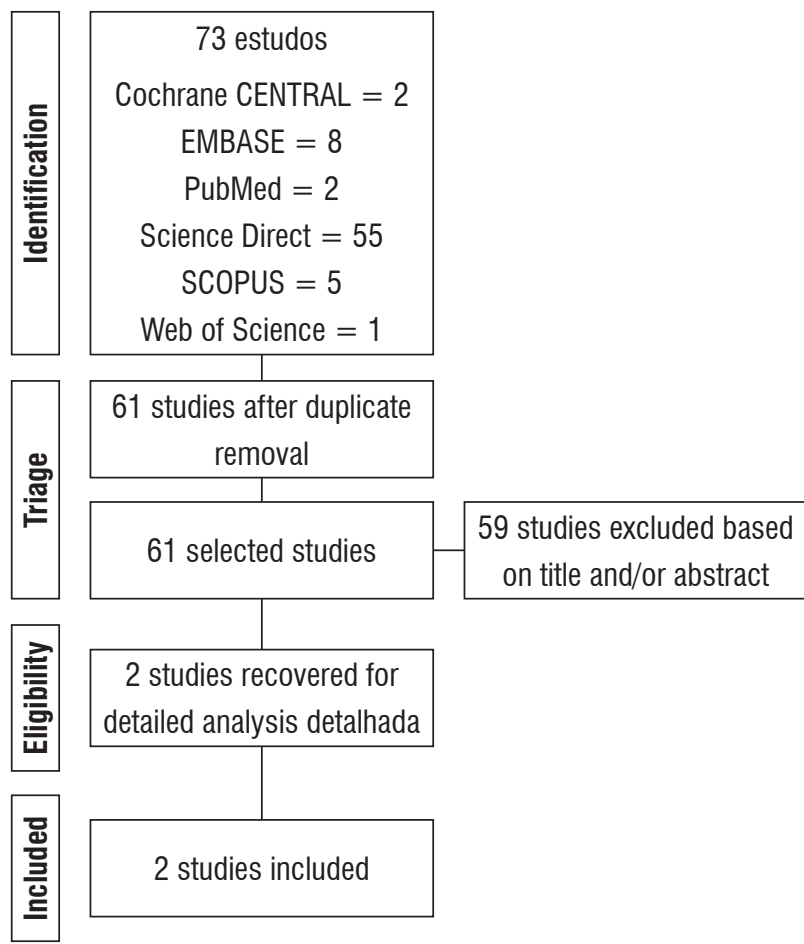

Figure 1 - Search flowchart 
Table 2 - Characteristics of the included studies

\begin{tabular}{|c|c|c|c|c|c|}
\hline Study, Year & Study type & Sample data & Intervention & Evaluation & Results \\
\hline $\begin{array}{l}\text { Dunleavy } \\
\text { et al. [17] }\end{array}$ & NRCT & $\begin{array}{l}\text { Chronic neck pain } \\
N=56 \\
\text { ( } 49 \text { women and } 7 \text { men; } \\
\text { age } 55.6 \pm 9 \text { ) } \\
\text { Pilates group: } n=20 \\
\text { Yoga group: } n=19 \\
\text { Control group: } n=17\end{array}$ & $\begin{array}{l}\text { Duration and Frequency: } \\
12 \text { weeks, once a week } \\
\text { (60 min) } \\
\text { Pilates group: Pilates } \\
\text { exercises on the ground } \\
\text { Yoga group: Adapted Yoga } \\
\text { exercises } \\
\text { Control group: no } \\
\text { intervention }\end{array}$ & $\begin{array}{l}\text { - Evaluations: weeks 0, 6, } \\
12 \text { and } 18 \\
\text { - Functional incapacity (NDI } \\
\text { - Neck Disability Index) } \\
\text { - Pain Intensity Evaluation } \\
\text { (NRS - Numeric pain } \\
\text { rating scale) }\end{array}$ & $\begin{array}{l}\text { - NDI: } \downarrow \text { in the Pilates and } \\
\text { Yoga groups at week } 12 \text {; } \\
\text { - NRS: } \downarrow \text { in average pain in } \\
\text { the } 12^{\text {th }} \text { week compared } \\
\text { to the } 6^{\text {th }} \text { week in the } \\
\text { Pilates group; } \leftrightarrow \text { pain in } \\
\text { the upper limb; and } \downarrow \text { pain } \\
\text { in sustained activity from } \\
\text { the } 6^{\text {th }} \text { week in the Pilates } \\
\text { and Yoga groups; } \\
\text { - No difference comparing } \\
\text { results from weeks } 12 \\
\text { and } 18 \text {. }\end{array}$ \\
\hline $\begin{array}{l}\text { Cazotti et al. } \\
\text { [27] }\end{array}$ & $\mathrm{RCT}$ & $\begin{array}{l}\text { Chronic neck pain } \\
n=64 \\
\text { (age 18-65) } \\
\text { Pilates group: } n=32 \\
\text { Control group: } n=32\end{array}$ & $\begin{array}{l}\text { Duration and Frequency: } \\
12 \text { weeks, twice a week } \\
\text { Pilates group: Pilates } \\
\text { exercises and drug } \\
\text { maintenance } \\
\text { Control group: drug } \\
\text { maintenance only }\end{array}$ & $\begin{array}{l}\text { - Evaluations: pre- } \\
\text { intervention, and after } 45 \text {, } \\
90 \text { and } 180 \text { days } \\
\text { - Functional incapacity (NDI } \\
\text { - Neck Disability Index) } \\
\text { - Pain Intensity Evaluation } \\
\text { (AVS - Analogic visual } \\
\text { scale) }\end{array}$ & $\begin{array}{l}\text { - The Pilates group, in } \\
\text { comparison to the } \\
\text { control group, presented } \\
\text { improvement of pain and } \\
\text { functionality. }\end{array}$ \\
\hline
\end{tabular}

Note: Caption: ECNR: Non-Randomized Clinical Trial; ECR: Randomized Clinical Trial.

Based on the evaluation of the methodological quality and risk of bias, taking into account the obtained scores and the type of included studies (Tables 2 and 3), the present systematic review presents moderate evidence. Since one of the studies comprised only an expanded abstract version [27] in its entirety, its score was lower, and its evaluation and interpretation were impaired.

Table 3 - Score of the studies on the Downs and Black scale [25]

\begin{tabular}{|c|c|c|c|}
\hline & \multirow[b]{2}{*}{ SCALE ITEM } & \multicolumn{2}{|c|}{ INCLUDED STUDIES } \\
\hline & & $\begin{array}{l}\text { Dunleavy } \\
\text { et al. [17] }\end{array}$ & $\begin{array}{l}\text { Cazotti et } \\
\text { al. [27] }\end{array}$ \\
\hline 1 & Clear hypothesis/objective & 1 & 1 \\
\hline 2 & Measured Outcomes & 1 & 1 \\
\hline 3 & $\begin{array}{l}\text { Characteristics of the individuals } \\
\text { included }\end{array}$ & 1 & 1 \\
\hline 4 & Interventions & 1 & 1 \\
\hline 5 & Distribution of the confusion factors & 1 & 1 \\
\hline 6 & Findings and conclusions & 1 & 0 \\
\hline 7 & Variability estimates & 1 & 0 \\
\hline 8 & Adverse effects & 0 & 0 \\
\hline 9 & Characteristics of lost individuals & 1 & 0 \\
\hline 10 & Confidence intervals and $p$ values & 1 & 1 \\
\hline
\end{tabular}

(To be continued)
(Conclusion)

Table 3 - Score of the studies on the Downs and Black scale [25]

\begin{tabular}{|c|c|c|c|}
\hline & \multirow[b]{2}{*}{ SCALE ITEM } & \multicolumn{2}{|c|}{ INCLUDED STUDIES } \\
\hline & & $\begin{array}{l}\text { Dunleavy } \\
\text { et al. [17] }\end{array}$ & $\begin{array}{l}\text { Cazotti et } \\
\text { al. [27] }\end{array}$ \\
\hline 11 & $\begin{array}{l}\text { Individuals representative of the } \\
\text { population }\end{array}$ & 0 & 0 \\
\hline 12 & Representative $\%$ of individuals & 0 & 0 \\
\hline 13 & Representative team and location & 1 & 0 \\
\hline 15 & Evaluator blinding & 0 & 1 \\
\hline 16 & Data dredging & 1 & 1 \\
\hline 17 & Analyses adjusted over time & 1 & 1 \\
\hline 18 & Adequate statistical tests & 1 & 1 \\
\hline 19 & Adherence to the intervention & 1 & 1 \\
\hline 20 & Accurate outcome measurement & 1 & 0 \\
\hline 21 & $\begin{array}{l}\text { Individuals from groups recruited } \\
\text { from the same population }\end{array}$ & 1 & 0 \\
\hline 22 & $\begin{array}{l}\text { Individuals recruited during the } \\
\text { same period }\end{array}$ & 1 & 0 \\
\hline 23 & Randomized individuals & 0 & 1 \\
\hline 25 & $\begin{array}{l}\text { Adjustment of the confusion } \\
\text { factors }\end{array}$ & 0 & 0 \\
\hline 26 & Losses taken into account & 1 & 0 \\
\hline & Power of the study & 5 & 0 \\
\hline & Total & 23 & 12 \\
\hline
\end{tabular}




\section{Discussion}

Scientific research on the effects of the Pilates method on neck pain present methodological differences, but do not make comparisons unfeasible. Regarding the studies included herein, one was predominantly performed with adults [17] and the other with young and old individuals, characterizing a broader age group [27]. The divergences and particularities of each age group make it difficult to extrapolate and compare the results, since the elderly population presents associated health problems and poorer health self-perception [28, 29]. It should be pointed out that neck pain has become a public health problem, which directly affects individuals of the economically active population, in other words, adults, which is consistent with the sample design adopted in both studies included in this review, and in the studies included in the systematic review conducted by the Cervical Overview Group of the Cochrane Collaboration [12].

Most studies conducted to investigate the effect of Pilates exercise intervention include female participants, due to the profile of people that search and conduct the practice [30,31]. In addition, the incidence of neck pain is higher in women compared to men $[6,32,33]$, corroborating the sampling adopted in the studies $[17,34]$.

In the study conducted by Dunleavy et al. [17] the final sample, considering intention to treat the presented pain, was composed of 56 individuals. However, 90 individuals had been estimated to detect clinical differences through the Neck Disability Index [35]. On the other hand, in the study performed by Cazotti et al. [27], conducted with 64 individuals, individuals were not described per sex and the sample calculation was not reported, despite the fact that the adopted sample size was considerable. It should be noted that studies encompassing exercises as therapy for the treatment of neck pain, in turn, show a small sample size [12], which can lead to biases and generate type II errors.

Although the included studies were clinical trials, only one seems to have been methodologically conducted in a randomized fashion [27], and divergences in the number of listed groups were observed. Dunleavy et al. [17] conducted a controlled, almost randomized, parallel study and chose to split the sample into three groups, one control and two undergoing interventions, one with Pilates exercises and the other with Yoga. Cazotti et al. [27] conducted their study with an intervention group with Pilates and drug maintenance and a control group with drug maintenance only, which may have masked information related to pain results, since the medication had an active principle focused on pain relief. The results of the comparisons between groups were presented in both included studies [17, 27], while in the study performed by Dunleavy et al. [17] the results isolated by group over time were also provided, facilitating extrapolation of the findings and understanding of the effects of the practice.

Regarding the type of intervention, Dunleavy et al. [17] adopted solo Pilates exercises guided by physiotherapists trained in the method, focusing on stabilization, mobilization and strengthening of the extensor muscles of the spine, with greater focus on the shoulder girdle, in classes performed with groups composed of four to eight individuals. This protocol was similar to that adopted in the study conducted by Mallin \& Murphy [34], with individuals with chronic neck pain, although these authors prioritized the pelvic girdle in their approach. However, it is not clear what exercise protocol was adopted in the study conducted by Cazotti et al. [27]. The preference for ground exercises may be due to low costs and ease of execution regarding physical space and the fact that they can be taught to larger groups, as well as the fact that exercise resistance is only generated by the action of gravity and not exacerbated by the use of accessories, such as occurs when using equipment springs.

The frequency of the sessions in the study performed by Dunleavy et al. [17] consisted of a weekly intervention lasting 60 minutes, also adopted by Mallin \& Murphy [34], although these authors still recommend complementary home practice. On the other hand, Cazotti et al. [27] preferred to adopt a frequency of twice a week, which has been observed in other studies conducted with Pilates [26, 36]. In both studies, the duration of the intervention consisted of 12 weeks $[17,27]$, accounting for a total of 12 sessions in the report by Dunleavy et al. [17] and 24 in the study by Cazotti et al. [27]. It should be noted that, in a recent systematic review with metaanalysis on the effects of exercise on neck pain [37], authors observed that an intervention frequency of three times a week was the most adopted and, therefore, indicated, since this frequency results in pain improvement, strength, quality of life and functional capacity $[38,39]$. 
We emphasize the importance of performing exercises under the guidance and supervision of a trained professional, mainly by individuals seeking the practice for pain relief, for, although home exercise programs are important for maintenance, they can be performed incorrectly, reinforcing the adoption of inadequate movement strategies [17]. In addition, it is extremely important that the exercise protocols in the studies be evidenced, in order to allow for replication in research and clinical practice.

Investigative approaches regarding pain and functionality were conducted in the included studies [17, 27], since these variables are directly related to each other. Pain was measured in the study performed by Dunleavy et al. [17] by means of the Numerical Pain Classification Scale, which quantifies the intensity of the pain through a numerical categorization from zero to 10 , through questions regarding pain during the last week (in order to characterize the pre-intervention groups), pain caused by activities related to upper limb movements and pain caused by sustained tasks. Cazotti et al. [27] opted to use the Visual Analogue Scale, which consists of a 10 centimeter horizontal line, designed to quantitatively assess pain in both clinical and research situations [40], approached comprehensively.

Functionality was evaluated in both studies using the Neck Disability Index [17, 27], which consists of 10 questions related to pain and daily living activities (pain intensity, personal care, concentration, work, driving, sleeping and recreation), with responses in the Likert scale format ( 0 - 5). A maximum score of 50 can be obtained, where higher values indicate greater disability [35]. It should be noted that all the adopted evaluation instruments are valid and reproducible, leading to more robust and reliable results.

In the study conducted by Dunleavy et al. [17] the evaluations were performed before the beginning of the study, in the $6^{\text {th }}, 12^{\text {th }}$ and $18^{\text {th }}$ weeks, the latter referring to the follow-up, performed after six weeks of the end of the practice. In the study performed by Cazotti et al. [27] pre-intervention evaluations were carried out after 45, 90 and 180 days, or, in weekly approaches, at week zero, six, 13 and 26, and the follow-up was conducted at an interval of 13 weeks. It is important to point out the importance of conducting evaluations after an intervention pause period, which allows for the verification of the preservation of the obtained benefits.
Significant functionality improvement with Pilates exercises was observed in the included studies [17, 27]. Dunleavy et al. [17] observed better results in the groups submitted to the intervention in the $12^{\text {th }}$ week compared to the $6^{\text {th }}$, after the end of 12 sessions, which was not observed in the control group. This corroborates the report by Mallin \& Murphy [34], who also observed improvement in this variable after six sessions. However, evidence is still of low quality regarding the benefits related to functionality arising from interventions with exercises in long-term follow-ups [12]. Moreover, in the study performed by Dunleavy et al. [17], Pilates had greater effect than Yoga when compared to the control group, and only Pilates promoted improvement from the $6^{\text {th }}$ week onwards. However, in the study conducted by Mallin \& Murphy [34], a preservation in the improvement of the functionality after six weeks of the end of the intervention was observed, while in the study conducted by Dunleavy et al. [17] no difference was observed comparing the $12^{\text {th }}$ and $18^{\text {th }}$ weeks.

The decrease of pain with the Pilates intervention was unanimous in the included studies [17, 27]. In the study performed by Dunleavy et al. [17], pain caused by sustained tasks decreased from the $6^{\text {th }}$ week of intervention, with lower values and nearremission after 12 weeks in the groups submitted to the intervention. Meanwhile, the average pain in the Pilates group was lower in the $12^{\text {th }}$ week compared to the $6^{\text {th }}$, and the same when compared to the control group, with Pilates displaying a significant effect. However, no significant difference was observed in relation to pain caused by upper limb movements in all analyzed groups, as well as in the follow-up evaluation after six weeks of the end of the intervention. In the same study, the group submitted to the Yoga intervention also presented pain decreases in comparison to the control group, but with moderate effect size. Cazotti et al. [27] also observed significant pain improvement, however, they did not make it clear from which week. These results are in line with what has been observed in other systematic literature reviews, which demonstrate the benefits of exercise therapies in the decrease and remission of pain $[12,41]$.

Based on the above, despite the small number of studies carried out to investigate the effects of Pilates on individuals with neck pain, we emphasize 
their considerable quality and methodological rigor, which provides basis for the reproduction of the described protocols in the clinical practice, adding to the guidance of the prescription of exercises by instructors with training in the Method.

\section{Conclusion}

The present systematic review presents moderate evidence to support the indication and practice of Pilates exercises by individuals with chronic neck pain, since this method promotes functional and functional improvement after a short period of time. It is suggested that studies with higher quality and methodological rigor, such as randomized clinical trials, be conducted, so that evidence of this practice recommendation can be confirmed.

\section{References}

1. Cassidy JD, Côté P. Is it time for a population health approach to neck pain? J Manipulative Physiol Ther. 2008;31(6):442-6.

2. Kapreli E, Vourazanis E, Billis E, Oldham JA, Strimpakos N. Respiratory dysfunction in chronic neck pain patients A pilot study. Cephalalgia. 2009;29(7):701-10.

3. Ariëns GAM, Borghouts JAJ, Koes BW. Neck pain. In: Crombie IK, Croft PR, Linton SJ, LeResche L, Korff M, editors. Epidemiology of pain. Seattle: IASP Press; 1999. p. 235-56.

4. Barnes PM, Bloom B, Nahin RL. Complementary and alternative medicine use among adults and children: United States, 2007. Natl Health Stat Report. 2008;(12):1-23.

5. Borges MC, Borges CS, Silva AGJ, Castellano LRC, Cardoso FAG. Avaliação da qualidade de vida e do tratamento fisioterapêutico em pacientes com cervicalgia crônica. Fisioter Mov. 2013;26(4):873-81.

6. Fejer R, Kyvik KO, Hartvigsen J. The prevalence of neck pain in the world population: a systematic critical review of the literature. Eur Spine J. 2006;15(6):834-48.
7. Carroll LJ, Hogg-Johnson S, Van der Velde G, Haldeman S, Holm LW, Carragee EJ, et al. Course and prognostic factors for neck pain in the general population: results of the Bone and Joint Decade 2000-2010 Task Force on Neck Pain and Its Associated Disorders. J Manipulative Physiol Ther. 2009;32(2 Suppl):S87-96.

8. Ferreira GD, Silva MC, Rombaldi AJ, Wrege ED, Siqueira FV, Hallal PC. Prevalência de dor nas costas e fatores associados em adultos do Sul do Brasil: estudo de base populacional. Revista bras fisioter. 2011;15(1):31-6.

9. Makela M, Heliovaara M, Sievers K, Impivaara O, Knecht P, Aromaa A. Prevalence, determinants and consequences of chronic neck pain in Finland. Am J Epidemiol. 1991;134(11):1356-67.

10. Bovim G, Schrader H, Sand T. Neck pain in the general population. Spine. 1994;19(12):1307-9.

11. Gross A, Forget M, St George K, Fraser MM, Graham $\mathrm{N}$, Perry L, et al. Patient education for neck pain. Cochrane Database Syst Rev. 2012;(3):CD005106.

12. Gross A, Kay TM, Paquin JP, Blanchette S, Lalonde P, Christie T, et al. Exercises for mechanical neck disorders. Cochrane Database Syst Rev. 2015;1:CD004250.

13. Childs JD, Cleland JA, Elliott JM, Teyhen DS, Wainner RS, Whitman JM, et al. Neck pain: Clinical practice guidelines linked to the International Classification of Functioning, Disability, and Health from the Orthopedic Section of the American Physical Therapy Association. J Orthop Sports Phys Ther. 2008;38(9):A1-A34.

14. Scholten-Peeters GG, Bekkering GE, Verhagen AP, van Der Windt DA, Lanser K, Hendriks EJ, et al. Clinical practice guideline for the physiotherapy of patients with whiplash-associated disorders. Spine (Phila Pa 1976). 2002;27(4):412-22.

15. Falla D. Unravelling the complexity of muscle impairment in chronic neck pain. Man Ther. 2004;9(3):125-33.

16. Cohen SP. Epidemiology, diagnosis, and treatment of neck pain. Mayo Clini Proc. 2015;90(2):284-99.

17. Dunleavy K, Kava K, Goldberg A, Malek MH, Talley SA, Tutag-Lehr V, et al. Comparative effectiveness of Pilates and yoga group exercise interventions for chronic mechanical neck pain: quasi-randomised parallel controlled study. Physiotherapy. 2016;102(3):236-42. 
18. Kuo YL, Tully EA, Galea MP. Sagittal spinal posture after Pilates-based exercise in healthy older adults. Spine. 2009;34(10):1046-51.

19. Emery K, De Serres SJ, McMillan A, Côté JN. The effects of a Pilates training program on arm-trunk posture and movement. Clin Biomech. 2010;25(2):124-30.

20. Sinzato CR, Taciro C, Pio CA, De Toledo AM, Cardoso JR, Carregaro RL. Efeitos de 20 sessões do Método Pilates no alinhamento postural e flexibilidade de mulheres jovens: estudo piloto. Fisioter Pesq. 2013;20(2):143-50.

21. Galvão TF, Pereira MG. Revisões sistemáticas da literatura: passos para sua elaboração. Epidemiol Serv Saúde. 2014;23(1):183-4.

22. Moher D, Liberati A, Tetzlaff J, Altman DG. Preferred reporting items for systematic reviews and meta-analyses: the PRISMA statement. Int J Surg. 2010;8(8):336-41.

23. Higgins J, Green S. Cochrane handbook for systematic review of interventions. The Cochrane Colaboration. 2010.

24. Pereira MG, Galvão TF. Etapas de busca e seleção de artigos em revisões sistemáticas da literatura. Epidemiol Serv Saúde. 2014;23(2):369-71.

25. Downs SH, Black N. The feasibility of creating a checklist for the assessment of the methodological quality both of randomised and non-randomised studies of health care interventions. J Epidemiol Community Health. 1998;52(6):377-84.

26. Van Tulder MW, Koes BW, Bouter LM. Conservative treatment of acute and chronic nonspecific low back pain: A systematic review of randomized controlled trials of the most common interventions. Spine. 1997;22(18):2128-56.

27. Cazotti LA, Jones A, Silva DR, Ribeiro LHC, Natour J. Effectiveness of Pilates Method for the treatment of chronic mechanical neck pain. Arthritis Rheum. 2013;65:S776-7.

28. Hartvigsen J, Christensen K, Frederiksen H. Back pain remains a common symptom in old age. A populationbased study of 4486 Danish twins aged 70-102. Eur Spine J. 2003;12(5):528-34.
29. Maiers M, Bronfort G, Evans R, Hartvigsen J, Svendsen K, Bracha Y. Spinal manipulative therapy and exercise for seniors with chronic neck pain. Spine J. 2014;14(9):1879-89.

30. Segal NA, Hein J, Basford JR. The effects of Pilates training on flexibility and body composition: an observational study. Arch Phys Med Rehabil. 2004;85(12):1977-81.

31. Herrington L, Davies R. The influence of Pilates training on the ability to contract the transversus abdominus muscle in asymptomatic individuals. J Bodyw Mov Ther. 2005;9(1):52-7.

32. Webb R, Brammah T, Lunt M, Urwin M, Allison T, Symmons D. Prevalence and predictors of intense, chronic, and disabling neck and back pain in the UK general population. Spine. 2003;28(11):1195-202.

33. Guez M, Hildingsson C, Nilsson M, Toolanen G. The prevalence of neck pain: a population-based study from northern Sweden. Acta Orthop Scand. 2002;73(4):455-9.

34. Mallin G, Murphy S. The effectiveness of a 6-week Pilates programme on outcome measures in a pouplation of chronic neck pain patients: a pilot study. J Bodyw Mov Ther. 2013;17(3):376-84.

35. MacDermid JC, Walton DM, Avery S, Blanchard A, Etruw E, McAlpine C, et al. Measurement properties of the neck disability index: a systematic review. J Orthop Sports Phys Ther. 2009;39(5):400-17.

36. Junges S, Gottlieb MG, Baptista RR, Quadros CB, Resende TL, Gomes I. Eficácia do método Pilates para a postura e flexibilidade em mulheres com hipercifose. R bras Ci e Mov. 2012;20(1):21-33.

37. O'Riordan C, Clifford A, Van De Ven P, Nelson J. Chronic neck pain and exercise interventions: frequency, intensity, and type principle. Arch Phys Med Rehabil. 2014;95(4):770-83.

38. Chiu TT, Lam TH, Hedley AJ. A randomized trial on the efficacy of exercise for patients with chronic neck pain. Spine (Phila Pa 1976). 2005;30(1):E1-7. 
39. Ylinen J, Takala EP, Nykänen M, Häkkinen A, Mälkiä E, Pohjolainen T, et al. Active neck muscle training in the treatment of chronic neck pain in women: a randomized controlled trial. JAMA. 2003;289(19):2509-16.

40. Vogt L, Segieth C, Banzer W, Himmelreich H. Movement behaviour in patients with chronic neck pain. Physiother Res Int. 2007;12(4):206-12.
41. Salt E, Wright C, Kelly S, Dean A. A systematic literature review on the effectiveness of non-invasive therapy for cervicobrachial pain. Man Ter. 2011;16(1)53-65.

Received on $05 / 05 / 2016$

Recebido em 05/05/2016

Approved on 04/10/2017

Aprovado em 10/04/2017 